Pacific Journal of Mathematics

COHERENT POLYNOMIAL RINGS OVER REGULAR RINGS 


\title{
COHERENT POLYNOMIAL RINGS OVER REGULAR RINGS OF FINITE INDEX
}

\author{
ANDREW B. CARSON
}

\begin{abstract}
It is shown that polynomial rings in finitely or infinitely many central indeterminates, over a regular ring of finite index, are right and left coherent.
\end{abstract}

In this paper all rings have unity and all ring homomorphisms preserve the unity.

Definition 1. A ring $R$ is:

(i) Regular, if it satisfies the sentence

$$
(\forall r)(\exists s)[r s r=r] ;
$$

(ii) Of index $n$, where $n \geqq 1$ is an integer, if for all $m \geqq n$, it satisfies the sentence

$$
(\forall r)\left[r^{m}=0 \longrightarrow r^{n}=0\right] ;
$$

(iii) Of finite index if it is of index $n$, for some integer $n \geqq 1$.

Definition 2. A ring $R$ is left coherent if:

(i) $U \cap V$ is a finitely generated left ideal in $R$, whenever $U$ and $V$ are finitely generated left ideals in $R$, and

(ii) For each $r \in R$, the left annihilator of $r$ in $R$ is finitely generated, as a left ideal in $R$.

Right coherence for $R$ is similarly defined.

Definition 3. Let $f$ be an element of and $I$ a finite subset of a polynomial ring $T\left[X_{1}, \cdots, X_{q}\right]$. Then:

(i) $\operatorname{deg}(f)$ is the total degree of $f$,

(ii) $\operatorname{deg}(I)=\operatorname{Sup}\{\operatorname{deg}(f): f \in I\}$, and

(iii) $\langle I\rangle$ denotes the left ideal generated by $I$.

It is known (cf. [3, Theorem 2.2]) that a ring is left coherent iff each of its finitely generated left ideals is finitely presented. Thus, for certain homological applications, the left coherent rings seem to be a suitable generalization of the left Noetherian rings. In view of the Hilbert basis theorem (which states that $T[X]$ is left Noetherian if $T$ is), this suggests the following conjecture: if $R$ is a left coherent ring, then $R[X]$ is too. Soublin, in [11], disproved this conjecture, even when $R$ is commutative. However he showed 
that it does hold when $R$ is commutative and regular. (All regular rings are right and left coherent and all commutative regular rings have index 1.)

The main result of this paper is:

THeOREM 1. Let $R$ be a regular ring of finite index. Then the polynomial ring $R\left[\left\{X_{\alpha}\right\}\right]$ is left and right coherent, for any finite or infinite set $\left\{X_{\alpha}\right\}$ of central indeterminates.

In [1] we established this result in the special case when $R$ is also a commutative algebraic algebra over some field. To do this we effectively showed that the result held for any regular ring that can be embedded in a ring $S$ such that, for each $q \geqq 1, S\left[X_{1}, \cdots, X_{q}\right]$ is left and right coherent. We then showed that, in this case, suitable $S$ actually exist.

For the rest of this paper let $R$ be an arbitrary regular ring of finite index, and let $q \geqq 1$ be any fixed integer. The following lemma yields Theorem 1:

LEMma 1. There exists a ring $S$ containing $R$ as a subring such that $S\left[X_{1}, \cdots, X_{q}\right]$ is left and right coherent.

Our proof of Lemma 1 hinges upon Lemma 2. Our approach to Lemma 2 is model theoretic.

Basic concepts of model theory, such as a (well formed) formula, a free variable, and a bound variable are found in [9]. A sentence is a formula in which all variables are bound. Let $L$ denote the first order predicate calculus for rings.

The major obstacle in applying model theory to our problem is that many useful statements cannot be expressed in $L$. For example, there is no sentence in $L$ which is satisfied by, and only by, polynomial rings. Further, the statement " $f \in U$ ", where $U$ is an ideal in some ring, cannot be expressed in $L$. To overcome these difficulties, we note that certain formulae $\phi$, concerning polynomial rings in $X_{1}, \cdots, X_{q}$, can be translated as formulae $\Phi$ in $L$ such that for any ring $T, \phi$ holds in $T\left[X_{1}, \cdots, X_{q}\right]$ iff $\Phi$ holds in $T$.

Robinson observes (cf. [10, Chapter 5, §4]) that if $r$ and $n$ are fixed and we have bounds on the degrees of $f$ and of each $g_{i}$, then the formula for polynomials (in $X_{1}, \cdots, X_{q}$ ) over a division ring

$$
\left(\exists h_{1}\right) \cdots\left(\exists h_{r}\right)\left[f=\sum_{i=1}^{r} h_{i} g_{i} \text { and } \operatorname{deg}\left(h_{j}\right) \leqq n \text {, when } 1 \leqq j \leqq r\right]
$$

can be translated into a formula of $L$, in the above sense. The translation is a conjunction of certain formulae involving the 
coefficients of these polynomials. In this situation we shall always assume that $\operatorname{deg}(f) \leqq \max \left\{\operatorname{deg}\left(h_{i} g_{i}\right): 1 \leqq i \leqq r\right\}$. This bounds the number of variables required in the translation, in place of $f$. Further, there exists a function $r$ such that for any $n \geqq 1$, division ring $D$, and finite subset $K \subseteq D\left[X_{1}, \cdots, X_{q}\right]$ such that $\operatorname{deg}(K) \leqq n$, $\{f \in\langle K\rangle: \operatorname{deg}(f) \leqq n\}$ is a vector space over $D$ of dimension $\leqq r(n)$. This is because $\left\{f \in D\left[X_{1}, \cdots, X_{q}\right]: \operatorname{deg}(f) \leqq n\right\}$ is a vector space generated by those products $\pi$ of indeterminates satisfying deg $(\pi) \leqq n$. Thus $K$ may (and always will) be identified with a set $A=\left\{g_{1}, \cdots, g_{r(n)}\right\}$ (with repetitions if necessary) such that $\langle A\rangle=\langle K\rangle$.

For each $m$ and $n \geqq 1$ define predicates $\epsilon_{m, n}$ and $\subseteq_{m, n}$, where $f$ is a polynomial, $K=\left\{g_{1}, \cdots, g_{r(m)}\right\}$ satisfies $\operatorname{deg}(K) \leqq m$, and $K^{\prime}=$ $\left\{g_{1}^{\prime}, \cdots, g_{\left.r^{\prime} m+n\right)}^{\prime}\right\}$ satisfies $\operatorname{deg}\left(K^{\prime}\right) \leqq m+n$, by $f \in_{m, n} K$ iff (a) holds when $r=r(m)$; and $K^{\prime} \subseteq_{m, n} K$ iff $g_{i}^{\prime} \in_{m, n} K$, for all $g_{i}^{\prime} \in K$.

Using Robinson's observation, identify these predicates with their translations into $L$. Let $f \epsilon_{m, n}\left(K, K^{\prime}\right)$ be the conjunction

$$
\left[\left(f \in_{m, n} K\right) \wedge\left(f \epsilon_{m, n} K^{\prime}\right)\right],
$$

where $\operatorname{deg}\left(K^{\prime}\right) \leqq m$ too. Similarly define $G \subseteq_{m, n}\left(K, K^{\prime}\right)$. Let $f \notin_{m, n} K, K^{\prime} \nsubseteq_{m, n} K$, and $G \nsubseteq_{m, n}\left(K, K^{\prime}\right)$ be the negations of $f \in_{m, n} K$, $K^{\prime} \nsubseteq_{m, n} K$, and $G \nsubseteq_{m, n}\left(K, K^{\prime}\right)$, respectively.

Although not themselves in the first order language $L$, the traditional $\epsilon$ and $\subseteq$ are related to these predicates as follows, where $(m, n)$ and $\left(m^{\prime}, n^{\prime}\right)$ take values in $\{(m, n): \operatorname{deg}(K) \leqq m$ and $\left.\operatorname{deg}\left(K^{\prime}\right) \leqq m+n\right\}$ and in $\left\{\left(m^{\prime}, n^{\prime}\right): \operatorname{deg}(K) \leqq m^{\prime}\right.$ and $\left.\operatorname{deg}(f) \leqq m^{\prime}+n^{\prime}\right\}$, respectively:

$f \in\langle K\rangle$ iff $f \epsilon_{m^{\prime}, n^{\prime}} K$ for sufficiently large $n^{\prime}$,

$f \notin\langle K\rangle$ iff $f \notin_{m^{\prime}, n^{\prime}} K$ for all $n^{\prime}$,

$\left\langle K^{\prime}\right\rangle \subseteq\langle K\rangle$ iff $\left\langle K^{\prime}\right\rangle \subseteq{ }_{m, n}\langle K\rangle$ for sufficiently large $n$, and $\left\langle K^{\prime}\right\rangle \nsubseteq\langle K\rangle$ iff $\left\langle K^{\prime}\right\rangle \Phi_{m, n}\langle K\rangle$ for all $n$.

The next result is crucial in establishing Theorem 1.

LEMma 2. There exist (for each q) integral valued functions $\boldsymbol{M}(-)$ and $\boldsymbol{N}(-,-)$ such that for any division ring $D$ and finite subsets $I$ and $J$ of $D\left[X_{1}, \cdots, X_{q}\right]$, having degrees $\leqq$ some $m$, there is a subset $G$ such that:

(i) $G \leqq_{m, M(m)}(I, J)$ (so that $\left.\operatorname{deg}(G) \leqq m+\boldsymbol{M}(m)\right)$;

(ii) Whenever $f \in_{m, n}(I, J)$, then $f \in_{m+M(m), N(m, n)} G$;

and thus

(iii) $\langle G\rangle=\langle I\rangle \cap\langle J\rangle$.

If the result were false, it would be obvious to any model theorist (cf. [4]) that ultraproducts could be used to construct a division ring $E$ and finite subsets $I$ and $J$ of $E\left[X_{1}, \cdots, X_{q}\right]$ such that 
$\langle I\rangle \cap\langle J\rangle$ is not finitely generated. This would contradict the Hilbert basis theorem.

LemMA 3. If $S=\Pi\left\{D_{\alpha}: \alpha \in A\right\}$ is a product of division rings and $T=S\left[X_{1}, \cdots, X_{q}\right]$, then $T$ is left and right coherent.

Proof. By symmetry it suffices to show that $T$ is left coherent.

An element $s \in S$ is a function such that $s(\alpha) \in D_{\alpha}$, for each $\alpha \in A$. For any $t=\Sigma s_{i} \pi_{i} \in T$, where each $s_{i} \in S$ and each $\pi_{i}$ is a product of indeterminates, let $t(\alpha)=\Sigma s_{i}(\alpha) \pi_{i}$. For each subset $U$ of $T$ let $U_{\alpha}=\{u(\alpha): u \in U\}$. Clearly, if $U$ is a left ideal in $T$, then $U_{\alpha}$ is a left ideal in $T_{\alpha}$ and $T_{\alpha}=D_{\alpha}\left[X_{1}, \cdots, X_{q}\right]$, for each $\alpha \in A$.

To see that the left annihilator of any $t=\Sigma s_{i} \pi_{i} \in T$ is finitely generated (in fact generated by an idempotent) choose $e \in S$ such that $e(\alpha)=1$ if $t(\alpha)=0$, and $e(\alpha)=0$ otherwise. Clearly $T \cdot e$ is the left annihilator of $s$.

Now let $I$ and $J$ be finite subsets of $T$ and choose $m$ such that $\operatorname{deg}(I) \leqq m$ and $\operatorname{deg}(J) \leqq m . \quad$ For each $\alpha \in A, \operatorname{deg}\left(I_{\alpha}\right) \leqq m$ and $\operatorname{deg}\left(J_{\alpha}\right) \leqq m$ so that there exists a subset $G_{(\alpha)}=\left\{g_{\alpha, 1}, \cdots, g_{\alpha, s}\right\} \subseteq T_{\alpha}$ (where $s=\boldsymbol{r}(\boldsymbol{M}(m))$ ) such that conditions (i), (ii), and (iii) from Lemma 2 hold, when $I, J, G$, and $D$ are replaced by $I_{\alpha}, J_{\alpha}, G_{(\alpha)}$, and $D_{\alpha}$ respectively. Define a finite subset $G=\left\{g_{1}, \cdots, g_{s}\right\} \subseteq T$ by $g_{i}(\alpha)=g_{\alpha, i}$, for each $\alpha \in A$. We must now show that these $g_{i}$ actually exist. For any $i, g_{i} \in T$ exists as defined iff $\left\{\operatorname{deg}\left(g_{\alpha, i}\right): \alpha \in A\right\}$ is bounded above. By Lemma 2 (i), $m+\boldsymbol{M}(m)$ is such a bound.

We shall establish that $\langle I\rangle \cap\langle J\rangle=\langle G\rangle$. To see that $\langle I\rangle \cap$ $\langle J\rangle \leqq\langle G\rangle$ let $f \in\langle I\rangle \cap\langle J\rangle$ and $n=\operatorname{deg}(f)$. Then, for each $\alpha \in A$, $f(\alpha) \in\left\langle I_{\alpha}\right\rangle \cap\left\langle J_{\alpha}\right\rangle=\left\langle G_{\alpha}\right\rangle \subseteq\left\langle T_{\alpha}\right\rangle$. Lemma 2 (ii) yields elements $h_{\alpha, i} \in T_{\alpha}$ such that $f(\alpha)=\sum_{i=1}^{s} h_{\alpha, i} g_{i}(\alpha)$, and an upper bound, $N(m, n)$, to $\left\{\operatorname{deg}\left(h_{\alpha, i}\right): 1 \leqq i \leqq s\right.$ and $\left.\alpha \in A\right\}$. Thus there are elements $h_{i} \in T$ satisfying $h_{i}(\alpha)=h_{\alpha, i}$. Therefore $f=\sum_{i=1}^{s} h_{i} g_{i} \in\langle G\rangle$. The proof that $\langle G\rangle \subseteq\langle I\rangle \cap\langle J\rangle$ is similar, and uses Lemma 2 (i).

Proof of Lemma 1. Let $Q$ be the complete left quotient ring of $R$. By [2, Theorem A] there is an isomorphism

$$
Q \cong \bigoplus \sum_{i=1}^{a}\left(D_{i}\right)_{u(i)}
$$

where $a$ and the $u(i)$ are suitable integers, expressing $Q$ as a direct sum of matrix rings over regular rings $D_{i}$, of index 1 . For each $i$, let $S_{i}=\Pi\left\{D_{i} / M: M\right.$ is a maximal ideal in $\left.D_{i}\right\}$. Kaplansky has shown (cf. [8, Theorem 2.3]) that each $D_{i} / M$ is a division ring and there is an embedding $D_{i} \subseteq S_{i}$. Let $S=\bigoplus \sum_{i=1}^{a}\left(S_{i}\right)_{u(i)}$. Clearly $R \subseteq S$ and 


$$
S\left[X_{1}, \cdots, X_{q}\right] \cong \bigoplus \sum_{i=1}^{a}\left(S_{i}\left[X_{1}, \cdots, X_{q}\right]\right)_{u(i)} .
$$

By Lemma 3, each $S_{i}\left[X_{1}, \cdots, X_{q}\right]$ is left coherent. Thus [6, Corollary 2.2] establishes that each $\left(S_{i}\left[X_{1}, \cdots, X_{q}\right]\right)_{u(i)}$ is left coherent whence, by ${ }^{*}$ and ([7, Corollary 2.1], $S\left[X_{1}, \cdots, X_{q}\right]$ is too). Right coherence is established similarly.

REMARK 1. Let $\mathscr{C}$ be any class of rings closed under elementary equivalence. (I.e., if $D \in \mathscr{C}$ satisfies the same sentences from $L$ as $D^{\prime}$, then $D^{\prime} \in \mathscr{C}$.) The above methods may be used to show that if $D\left[X_{1}, \cdots, X_{q}\right]$ is (left) coherent for each $D \in \mathscr{C}$ and $S$ is a product of rings from $\mathscr{C}$, then $S\left[X_{1}, \cdots, X_{q}\right]$ is (left) coherent too. However proving this is somewhat cumbersome since the number of elements in various $G \leqq D\left[X_{1}, \cdots, X_{q}\right]$ having degree $\leqq m$, for various $D \in \mathscr{C}$, need not be bounded. This complicates the definitions of $\in_{m, n}, \subseteq_{m, n}$, and the statement and proof of Lemma 2. In addition, the $D\left[X_{1}, \cdots, X_{q}\right]$ need not be integral domains. Thus another lemma is required stating that there exist integral valued functions $A(-)$ and $\boldsymbol{B}(-,-)$ such that for each $D \in \mathscr{C}$ and $f \in D\left[X_{1}, \cdots, X_{q}\right]$ having degree $\leqq m$, there exists a subset

$$
\left\{g_{1}, \cdots, g_{A(m)}\right\} \subseteq D\left[X_{1}, \cdots, X_{q}\right] \quad \text { of degree } \leqq A(m)
$$

such that $G \cdot f=0$ and, if $k \cdot f=0$ and $\operatorname{deg}(k) \leqq n$, then there exist $h_{1}, \cdots, h_{A(m)}$ (each having degree $\leqq \boldsymbol{B}(m, n)$ ) such that

$$
k=\sum_{i=1}^{A(m)} h_{i} g_{i} \text {. }
$$

REMARK 2. In particular, for any fixed $n$, if $\mathscr{C}=\left\{(D)_{m}: m \leqq n\right.$ and $D$ is a division ring $\}$, then it is closed under elementary equivalence since, by [8, Theorem 2.3], it consists of regular rings of index $n$ satisfying

$$
(\forall e)\left(\left[e^{2}=e \wedge(\forall r)(r e=e r)\right] \rightarrow[e=0 \vee e=1]\right) .
$$

This provides an alternate proof of Lemma 1 . Suppose that $R$ is a regular ring of index $n$. Let $S=\Pi\{R / M: M$ is a maximal ideal in $R$. Since $R$ is regular, it is standard that the natural map $R \rightarrow S$ is an embedding. By [8, Theorem 2.3] each $R / M \in \mathscr{C}$. As in the proof of Lemma $1, T\left[X_{1}, \cdots, X_{q}\right]$ is left coherent, for each $T \in \mathscr{C}$. Thus, by Remark $1, S\left[X_{1}, \cdots, X_{q}\right]$ is left coherent.

REMARK 3. Our approach to Theorem 1 uses the structure results for regular rings of finite index obtained in [2] and [8]. We do not know if Theorem 1 also holds for arbitrary regular rings. 
REMARK 4. Eklof and Sabbagh have related coherence for rings to certain model theoretic concepts. They show (cf. [5, Theorem 3.16]) that a ring $\Lambda$ is coherent iff each ultraproduct of $\boldsymbol{\aleph}_{0}$-injective A-modules is $\aleph_{0}$-injective, and that (cf. [5, Theorems 4.1 and 4.8]) $\Lambda$ is coherent iff the elementary theory of its modules has a model completion. (A ring $\Lambda$ is $\aleph_{0}$-injective if, for each finitely generated ideal $U$ and $f \in \operatorname{Hom}(U, \Lambda)$, there exists $g \in \operatorname{Hom}(\Lambda, \Lambda)$ such that $\left.g\right|_{U}=f$.

\section{REFERENCES}

1. A. B. Carson, Coherence of polynomial rings over semi-simple algebraic algebras, Proc. Amer. Math. Soc., 34 (1972), 20-24.

2. - Representation of regular rings of finite index, J. Algebra, 39 (1976), $512-526$.

3. S. Chase, Direct products of modules, Trans. Amer. Math. Soc., 97 (1960), 457-473.

4. P. Eklof, Ultraproducts, Handbook of Math. Logic, Ed. J. Barwise, North Holland, Amsterdam.

5. P. Eklof and G. Sabbagh, Model-completions and modules, Ann. Math. Logic, 2 (1971), 251-295.

6. M. Harris, Some results on coherent rings, Proc. Amer. Math. Soc., 17 (1966), $474-479$.

7. _ Some results on coherent rings II, Glasgow Math. J., 8 (1967), 123-126.

8. I. Kaplansky, Topological representation of Algebras II, Trans. Amer. Math. Soc., 68 (1950), 62-75.

9. H. J. Keisler, Model Theory, North-Holland, Amsterdam, 1973.

10. A. Robinson, Introduction to Model Theory and to the Metamathematics of Algebra, North-Holland, Amsterdam, 1965.

11. J. Soublin, Un anneau cohérent dont l'anneau des polynômes n'est pas coherents, C. R. Acad. Sci., Paris, Sér. A-B, 267, A241-A243.

12. J. Barwise, Handbook of Mathematical Logic, North-Holland, Amsterdam, 1977.

Received March 9, 1976 and in revised form September 6, 1977. The author was supported by a National Research Council of Canada operating grant while conducting research for this paper.

UNIVERSITY OF SASKATCHEWAN

SASKatOON, SaSKatChEWAN

Canada S7N 0W0 


\section{PACIFIC JOURNAL OF MATHEMATICS}

\section{EDITORS}

RICHARD ARENS (Managing Editor)

University of California

Los Angeles, CA 90024

Charles W. Curtis

University of Oregon

Eugene, OR 97403

C. C. Moore

University of California

Berkeley, CA 94720

\section{J. DugundJI}

Department of Mathematics

University of Southern California

Los Angeles, CA 90007

R. FInN and J. Milgram

Stanford University

Stanford, CA 94305

\section{ASSOCIATE EDITORS}
E. F. BECKENBACH
B. H. NeumanN
F. WOLF
K. YoSHIDA

\section{SUPPORTING INSTITUTIONS}

\author{
UNIVERSITY OF BRITISH COLUMBIA \\ CALIFORNIA INSTITUTE OF TECHNOLOGY \\ UNIVERSITY OF CALIFORNIA \\ MONTANA STATE UNIVERSITY \\ UNIVERSITY OF NEVADA, RENO \\ NEW MEXICO STATE UNIVERSITY \\ OREGON STATE UNIVERSITY \\ UNIVERSITY OF OREGON
}

\author{
UNIVERSITY OF SOUTHERN CALIFORNIA \\ STANFORD UNIVERSITY \\ UNIVERSITY OF HAWAII \\ UNIVERSITY OF TOKYO \\ UNIVERSITY OF UTAH \\ WASHINGTON STATE UNIVERSITY \\ UNIVERSITY OF WASHINGTON
}

The Supporting Institutions listed above contribute to the cost of publication of this Journal, but they are not owners or publishers and have no responsibility for its content or policies.

Mathematical papers intended for publication in the Pacific Journal of Mathematics should be in typed form or offset-reproduced, (not dittoed), double spaced with large margins. Please do not use built up fractions in the text of the manuscript. However, you may use them in the displayed equations. Underline Greek letters in red, German in green, and script in blue. The first paragraph or two must be capable of being used separately as a synopsis of the entire paper. Items of the bibliography should not be cited there unless absolutely necessary, in which case they must be identified by author and journal, rather than by item number. Manuscripts, in triplicate, may be sent to any one of the editors. Please classify according to the scheme of Math. Reviews, Index to Vol. 39. All other communications should be addressed to the managing editor, or Elaine Barth, University of California, Los Angeles, California, 90024.

50 reprints to each author are provided free for each article, only if page charges have been substantially paid. Additional copies may be obtained at cost in multiples of 50 .

The Pacific Journal of Mathematics is issued monthly as of January 1966. Regular subscription rate: $\$ 72.00$ a year (6 Vols., 12 issues). Special rate: $\$ 36.00$ a year to individual members of supporting institutions.

Subscriptions, orders for numbers issued in the last three calendar years, and changes of address should be sent to Pacific Journal of Mathematics, 103 Highland Boulevard, Berkeley, California, 94708. Older back numbers obtainable from Kraus Periodicals Co., Route 100, Millwood, NY 10546.

PUBLISHED BY PACIFIC JOURNAL OF MATHEMATICS, A NON-PROFIT CORPORATION

Printed at Kokusai Bunken Insatsusha (International Academic Printing Co., Ltd.). 8-8, 3-chome, Takadanobaba, Shinjuku-ku, Tokyo 160, Japan.

Copyright (C) 1978 by Pacific Journal of Mathematics

Manufactured and first issued in Japan 


\section{Pacific Journal of Mathematics

Vol. 74, No. $2 \quad$ June, 1978

Aharon Atzmon, Spectral synthesis in some spaces of bounded continuous

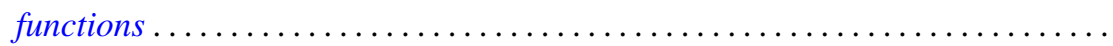

Karl Egil Aubert and Isidor Fleischer, Tensor products of ideal systems and their modules.............................................

Richard F. Basener, Several dimensional properties of the spectrum of a uniform

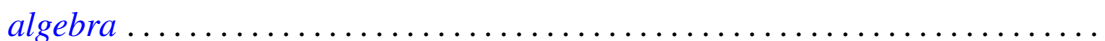

R. H. Bing and Michael Peter Starbird, Super triangulations ............. 307

Andrew Carson, Coherent polynomial rings over regular rings of finite index .....

Robert M. DeVos and Frederick W. Hartmann, Sequences of bounded summability domains .................................................

George Grätzer and R. Padmanabhan, Symmetric difference in abelian groups ....

Robert L. Griess, Jr., A remark about groups of characteristic 2-type and

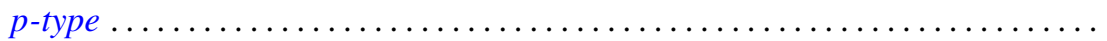

Emil Grosswald and F. J. Schnitzer, A class of modified $\zeta$ and L-functions........

Jutta Hausen and Johnny Albert Johnson, Ideals and radicals of some

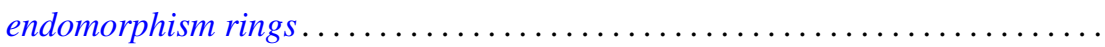

Jean Ann Larson, A solution for scattered order types of a problem of Hagendorf ............................................

Peter A. McCoy, Extremal properties of real biaxially symmetric potentials in $E^{2(\alpha+\beta+2)}$

Héctor Alfredo Merklen, Hereditary crossed product orders .

Hal G. Moore and Adil Mohamed Yaqub, Equational definability of addition in certain rings...

Robert Laurens Moore, Reductivity in $C^{*}$-algebras and essentially reductive operators. . .

Joseph Alvin Neisendorfer, Lie algebras, coalgebras and rational homotopy theory for nilpotent spaces...

William Raymond Nico, Bounded monoids

Richard Paul Osborne, Simplifying spines of 3-manifolds ...

Richard Paul Osborne, The simplest closed 3-manifolds. With an appendix by Osborne and J. Yelle.

Clayton Collier Sherman, The $K$-theory of an equicharacteristic discrete valuation ring injects into the $K$-theory of its field of quotients.... .

Mitchell Herbert Taibleson, The failure of even conjugate characterizations of $H^{1}$

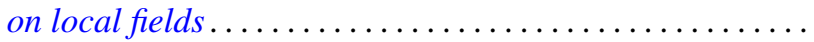

Keti Tenenblat, On characteristic hypersurfaces of submanifolds in Euclidean space ...................................

Jeffrey L. Tollefson, Involutions of Seifert fiber spaces..........

Joel Larry Weiner, An inequality involving the length, curvature, and torsions of a curve in Euclidean $n$-space .......................

Neyamat Zaheer, On generalized polars of the product of abstract homogeneous polynomials.... 